\title{
HIV testing of children is not simple for health providers and researchers: Legal and policy frameworks guidance in South Africa
}

\begin{abstract}
H E van Rooyen, A E Strode, C M Slack
Heidi van Rooyen, PhD, is an Executive Director in the Human and Social Development Programme at the Human Sciences Research Council, Durban, South Africa. A social scientist with a PhD in psychology, she has worked in the HIV field for the past 24 years in various capacities from counselling, training, clinical and academic supervision, mentoring and community-based research to policy development. Ann Strode, PhD, is a lawyer and Catherine Slack, PhD, a clinical psychologist. They have worked with the HIV/AIDS Vaccines Ethics Group (HAVEG) in the School of Applied Health Sciences, University of KwaZulu-Natal, Pietermaritzburg, South Africa, since 2000 to explore and strengthen the ethical-legal framework for the conduct of HIV vaccine trials. Both have a special interest in the participation of children and adolescents in research.
\end{abstract}

Corresponding author: $H$ van Rooyen (hvanrooyen@hsrc.ac.za)

\begin{abstract}
Antiretroviral treatment coverage for children and adolescents is significantly lower than that for adults. A first step in improving this situation is ensuring increased access to HIV counselling and testing services. Current legal and policy frameworks outline four norms that should inform HIV testing of children in South Africa: limiting HIV testing to defined circumstances, and ensuring that consent is obtained, counselling is provided and confidentiality is maintained. Implementing these norms is not simple, and we discuss the challenges and opportunities they present for children, their families, health providers and researchers working in this area. Better alignment between evolving public health approaches and the HIV counselling and testing legal/policy frameworks (and the internal coherence of domestic frameworks) would better serve children, their parents and those who work with them.
\end{abstract}

S Afr Med J 2016;106(5):451-453. DOI:10.7196/SAMJ.2016.v106i5.10484

Less than $30 \%$ of HIV-infected children are currently accessing antiretroviral therapy (ART) in South Africa (SA), with ART coverage for children and adolescents significantly lower than for adults. ${ }^{[1]}$ Ensuring better ART coverage requires improving access to and providing better HIV counselling and testing (HCT) services for children. This could lead to earlier diagnosis of HIV-positive children, more effective care, and reduced mortality. ${ }^{[2,3]}$ HIV testing of children is no simple matter, raising complexities for parents, caregivers and children and for the health professionals and researchers who work with them. We outline the four legal norms governing HCT of children in SA, and discuss the challenges and opportunities these present for children, their families, and practitioners and researchers working in this area.

\section{The four norms}

HIV testing is regulated through four key norms in the Children's Act 38 of 2005. ${ }^{[4]}$ Additional direction is provided in the National HIV Counselling and Testing Policy Guidelines ${ }^{[5]}$ and the 2012 Implementation Guidelines, which provide legal, ethical and counselling guidance for testing children and adolescents. ${ }^{[6,7]}$ The four norms that pertain to HIV testing of children are: (i) limiting HIV testing to defined circumstances; (ii) ensuring that consent is obtained; (iii) ensuring that counselling is provided; and (iv) ensuring that confidentiality is maintained.

\section{Limiting HIV testing to defined circumstances}

The Children's Act states that children may only be tested for HIV if it is in their best interests. ${ }^{[4]}$ Most HIV testing will be in the child's best interests, as knowledge of their HIV status will facilitate access to HIV prevention services and ART. This means that for HIV testing (unlike most other health interventions, where a procedure may be undergone for any reason) it must be demonstrated that it is in the child's best interests. ${ }^{[8]}$ Determining 'best interests' involves the practitioner assessing whether the testing will promote the child's physical, moral, emotional and spiritual welfare. ${ }^{[9-11]}$ Examples of when testing is in the child's best interests include testing babies born to HIV-positive mothers and testing child survivors of sexual assault. In HIV prevention trials, it is possible that enrolled participants may falsely believe that they are assigned the experimental product or that the product will protect them, and therefore increase risky behaviours; it is also important to identify HIV infections in order to take participants 'off-product'. In this context, testing would be in the best interests of the child if it was accompanied by risk reduction counselling tailored to their circumstances. ${ }^{[12]}$ In these instances, and many others, children can benefit from HIV testing, especially where it enables them to access to HIV treatment and care.

The second circumstance in which testing of children can take place is in the case of potential occupational exposure where a healthcare worker or a third party may have been exposed to HIV from contact with the child's body fluids. ${ }^{[4]}$ Testing children under this circumstance is likely to occur less frequently.

\section{Consent}

Any child aged $>12$ years may consent independently to an HIV test according to the Children's Act, ${ }^{[4,8]}$ which means that if such a child requests an HIV test they should be assisted to access one. Children aged $<12$ years may only consent independently to HIV testing if they have 'sufficient maturity to understand the benefits, risks and social implications of such a test. ${ }^{[4,8]}$

A child must be offered the test provided they meet the age or maturity standard. A maturity assessment requires that the conductor of the test be satisfied that the child understands the benefits (e.g. assessing ART and knowledge of prevention), the risks (e.g. stress from receiving a positive diagnosis) and the social implications (e.g. possible stigma or parental disapproval) that may accompany an HIV test. The 
child's circumstances at the time (i.e. their age, knowledge, experience and judgement) should also be taken into account. ${ }^{[6,7]}$

If a third party may have been exposed to HIV from contact with a child's body fluids, consent should be obtained from the child or their proxy to conduct the HIV test. If consent is refused and a healthcare worker has potentially been exposed to HIV, the test may be done without consent. ${ }^{[4]}$ If a third party who is not a healthcare worker may have been exposed to HIV and the child or their caregiver refuses to give consent to the test, a court order for the non-consensual testing will have to be obtained. ${ }^{[4]}$

HIV testing may be initiated by a service provider, guardian or caregiver or by the child themselves. However, even if testing is parent or provider initiated, the child aged $>12$ years must freely consent to the process, and the caregiver must consent if the child is aged $<12$ years. In the latter instance, the provincial head of the Department of Social Development can in exceptional circumstances be approached to provide consent to HIV testing of orphans and vulnerable children. ${ }^{[5]}$ As children can be easily persuaded, or feel they must comply with a request from a more powerful adult, the reasons why the child wishes to know their HIV status should always be explored. In HIV prevention trials, adolescents may be invited to consent to research exploring safety, efficacy or acceptability of HIV prevention products for this age group. Such research may involve specific components such as regular HCT. In this context, HCT is one of many trial procedures and is initiated by researchers. We have argued ${ }^{[8,13]}$ that adolescents aged $\geq 12$ years should self-consent to HIV testing in the trial despite their parents or guardians having provided consent to their participation.

\section{Counselling}

The Children's Act and the national HCT policy direct that HIV testing of children must be accompanied by proper pre- and posttest counselling by an appropriately trained person. ${ }^{[4,5]}$ This training should equip providers with the communication and counselling skills to work with the different developmental stages of childhood and adolescence. ${ }^{[6]}$ If the child's parent or caregiver is aware of the testing, he or she should also be involved in counselling. ${ }^{[4]}$ Counselling after testing enables the child (and parents) to be informed about the implications of the test result and referred for treatment, care and psychosocial services when needed. ${ }^{[5]}$

Healthcare providers should be aware that during the counselling children may disclose matters that trigger mandatory reporting, e.g. incidents of consensual but underage sex. ${ }^{[13,14]}$ Currently, there is no need to report consensual underage sex between 12 - 15-year-olds, or between those in this age group who have a partner aged 16 or 17 years, provided the gap between their ages is not $>2$ years. ${ }^{[13,14]}$ However, if there is a larger age gap, if one partner is an adult or if the child having sex is aged $<12$ years, reporting is still mandatory. ${ }^{[13,14]}$ Institutions providing HIV testing services to young people should ensure that staff are aware of when and how they should make such reports.

\section{Confidentiality}

The Children's Act and HCT policy hold that children who are capable of consent can decide who should know their HIV status. The national HCT policy recommends disclosure of a child's HIV positive status to a least one other person as being beneficial for psychosocial support and for adherence. We have argued ${ }^{[13]}$ that adolescents aged $\geq 12$ years who participate in research should be encouraged to disclose to a trusted adult within a reasonable timeframe.

\section{Discussion}

The increased availability of ART provides a compelling benefit to HIV testing of children. Despite this public health imperative, policy and guidelines for managing children at risk of and infected with HIV have often lagged behind those for adults. The current legal and policy guidelines provide much-needed guidance to practitioners and health researchers offering HCT services to children. ${ }^{[15]}$ While we hope that these norms will encourage greater testing of children, they have several constraints that may limit scale-up of testing services for children. These barriers must be addressed so that children have better access to HIV prevention and treatment services.

\section{The complexities for children and parents}

There are several reasons why offering HCT to children is complex. Firstly, testing children highlights the possibility of perinatal transmission of HIV. Testing children often raises serious implications for the child's mother and her own HIV status. Parents are often apprehensive about subjecting their children to HIV tests, especially when they are unsure of their own status. ${ }^{[16]}$ Parents may also fear being stigmatised and discriminated against if their child is HIV-positive and his or her status becomes known. These issues should be explored during counselling and appropriate coping strategies discussed.

Secondly, if the child did not consent to the test (either because they were perinatally infected or aged $<12$ ), disclosure to the child of his or her HIV status is required. Many parents and caregivers find it difficult to disclose a child's HIV positive status to them. ${ }^{[16]}$ Providers should respect parental wishes and views regarding disclosure of a child's HIV-positive status, but involvement of the child in this discussion should be encouraged and supported with appropriate disclosure strategies as the child develops. ${ }^{[6,7]}$ For all children, their extent of knowledge and understanding, emotional responses and stage of development will generally serve as a guide to when their status should be disclosed to them. ${ }^{[6,7,17-19]}$ Providers working with children and adolescents need appropriate training and support to facilitate these counselling conversations with parents, caregivers and other trusted adults, where appropriate, ${ }^{[13]}$ and with children.

Disclosure by adolescents to others may also be complex. The policies provide that children aged $\geq 12$ years may consent to and access HCT independently (without parental knowledge or permission). HIV infection at this age has usually been acquired through sex ${ }^{[20]}$ and these children may deny sexual activity, especially if counselled in the presence of a parent or guardian. Such children may have concerns that testing will inadvertently reveal their at-risk behaviours to parents, and about facing family or social disapproval for having engaged in underage sexual activity leading to HIV infection. ${ }^{[20]}$ However, many adolescents do not have the basic knowledge and skills to protect themselves from exposure to HIV, and have insufficient access to information, HCT, condoms, and treatment and care for sexually transmitted infections. ${ }^{[1]}$ All participants in HIV prevention trials, including adolescents, must be assured of access to a high standard of prevention, including these components. ${ }^{[12]}$ In the adolescent age group, the extent of parental involvement in decisions to test, and disclosure of test results, therefore merit careful consideration during counselling.

\section{Implications for healthcare providers}

The current ethical and legal frameworks recommend that children can consent independently to an HIV test from the age of 12 years. This acknowledges the right of a child to participate in decisions related to their own healthcare. ${ }^{[8,21]}$ However, requiring HIV testing to be in the best interests of the child means that healthcare providers need to determine the reason why the child wants to be tested for HIV. ${ }^{[8,21]}$ This may over-protect children because: $(i)$ it inappropriately limits the autonomy of older adolescents in electing to undergo HIV testing; (ii) it exceptionalises HIV testing by treating it differently to other sexual and reproductive services where this is not a requirement; and (iii) it is out of step with international best practice on HIV testing, which aims at normalising and integrating HIV testing into other health services. ${ }^{[2]}$ 
Acknowledging that children have a right to participate in matters that affect them creates a high standard for all who work with children. It may also place a burden on under-resourced, overstretched and often untrained lay workers who interface with children in health, social and welfare systems. Such providers may have to assess the child's best interests (for all children) and maturity to test (for children aged $<12$ years) based on limited information and within a short space of time. In HIV prevention trials, there may be fewer of these constraints. ${ }^{[10,13]}$

Scale-up of HIV testing for children in accordance with these norms requires investment in training, skills building and support of providers and should address the reluctance of healthcare providers to test children and ensure adequately trained staff to counsel children.

Other obstacles are the divergent approaches to the sexual and reproductive rights of children taken by the criminal law and the Children's Act. ${ }^{[13,14,21,23,24]}$ The Children's Act provides that children aged $\geq 12$ years can access a range of sexual and reproductive health services including contraceptives, HIV testing and treatment for sexually transmitted infections. Until recently, the Criminal Law (Sexual Offences and Related Matters) Amendment Act 32 of 2007 $7^{[25]}$ made it an offence to have consensual sex under the age of 16 years, and knowledge of this crime had to be reported 'immediately' to the police. This placed an obligation on all service providers, including healthcare providers and researchers, to report consensual underage sex or sexual activity to the police. ${ }^{[13,14,21,23]}$ The Constitutional Court found that the criminalisation of consensual sex between adolescents violated the constitutional rights of children to privacy and bodily integrity. ${ }^{[14,26]}$ Although the scope of criminalised consensual sex has been narrowed, reporting requirements remain in place. ${ }^{[14]}$

The lack of a common vision of when and how children should be offered HCT also hinders implementation of testing services to children. Confusion has been created about aspects of the recent Integrated School Health Policy (ISHP). ${ }^{[27]}$ The policy addresses the provision of comprehensive services for schoolgoing children and youth - including HCT for sexually active learners. However, it requires learners aged under 18 years to obtain the written consent of their parent or caregiver in order to access HCT. Furthermore, when consenting to individual services learners must be at least 14 years of age. This approach represents a disconnect between the positions taken in policy and in law. It is out of step with the Children's Act and the national HCT policy, and represents a disconnect in internal domestic policy that will cause confusion for service providers and children. Empirical research with stakeholders that explores: (i) their awareness of this disconnect in policy; and (ii) how they are responding to the incoherence is recommended. Furthermore, obtaining written consent from parents or caregivers to HCT may be an obstacle to some children accessing such services.

\section{Implications for researchers}

The ISHP policy for testing clashes with current recommendations governing children's participation in HIV prevention research. Generally, children aged $<18$ years require consent from a parent or legal guardian to participate in clinical trials, including HIV prevention trials (unless there are exceptional circumstances), ${ }^{[28]}$ but they should consent independently to various health procedures such as HCT from the age of 12 years. ${ }^{[8,13,21]}$ Obtaining parental consent for adolescent enrolment in HIV prevention trials requires a sound understanding of exactly what information parents will and will not have access to, and makes the consent process for both parents and children demanding but feasible. ${ }^{[13,21]}$

\section{Conclusion}

We are able to treat HIV as a chronic, long-term condition and must do more to increase access to HCT services and treatment for children. The legal and policy frameworks governing testing in SA children provide some guidance on how to proceed, but also create several complexities for children and parents, and those who work with them in various contexts. Better alignment between evolving public health approaches and the HCT legal/policy frameworks (and the internal coherence of domestic frameworks) would better serve children, their parents and those who work with them.

Acknowledgements and disclaimer. The work described here was supported by award number 1RO1 A1094586 from the National Institutes of Health (NIH) entitled CHAMPS (Choices for Adolescent Methods of Prevention in South Africa). The content is solely the responsibility of the authors and does not necessarily represent the official views of the NIH. The views of the authors are also not necessarily the views of any committee or council with which the authors are affiliated. Many thanks to Amin Matola for assistance with the referencing and manuscript preparation.

1. UNAIDS. Report on the Global AIDS Epidemic. Geneva: UNAIDS, 2012. http://www.unaids.org sites/default/files/media_asset/20121120_UNAIDS_Global_Report_2012_with_annexes_en_1.pdf (accessed 17 December 2015)

2. World Health Organization. HIV and Adolescents: HIV Testing and Counselling, Treatment and Care for Adolescents Living with HIV. Policy Brief. Geneva: WHO, 2013. http://apps.who.int/iris/ bitstream/10665/94561/1/9789241506526_eng.pdf (accessed 17 December 2015).

3. Kellerman S, Essajee S. HIV testing for children in resource-limited settings: What are we waiting for? PloS Med 2010;7:285-285. DOI:10.1371/journal.pmed.1000285

4. Government of South Africa. Children's Act: No. 38 of 2005. Pretoria: Government Printer, 2006 Government of South Africa. Childrens Act: No. 38 of 2005. Pretoria: Government Printer
http://www.plusto.com/uploads/5780/docs/Childrens-Act.pdf (accessed 17 December 2015).

5. National Department of Health. National HIV Counselling and Testing (HCT) Policy Guidelines. Pretoria National Department of Health. National HIV Counselling and Testing (HCT) Policy Guidelines. Pretoria:
NDoH, 2015. http://www.health-e.org.za/wp-content/uploads/2015/07/HCT-Guidelines-2015.pdf (accessed 17 NDoH, 2015. http

6. Grant K, Lazarus R, Strode A, van Rooyen H, Vujovic M. HIV Counselling and Testing of Children: Implementation Guidelines, 2012. http://www.hsrc.ac.za/uploads/pageContent/3181/HIVcounsellin andtestingofchildren-implementationguidelinesWEB.pdf (accessed 17 December 2015).

7. Grant K, Lazarus R, Strode A, van Rooyen H, Vujovic, M. HIV Testing of Children: Lega Guidelines for Implementers, 2012. http://www.hsrc.ac.za/uploads/pageContent/3181/ LegalGuidelinesforHIVTestingofChildrenWEB.pdf (accessed 17 December 2015).

8. Strode A, Slack C, Essack Z. Child consent in South African law: Implications for researchers, service providers and policy-makers. S Afr Med J 2010;100(4):247-249.

9. McCall v McCall 1994 (3) SA 201 (C)

0. Strode A, Slack C. Child research in South Africa: How do the new regulations help? S Afr Med J 2015;105(11):899-900. DOI:10.7196/SAMJ.2015.v105i11.9838

11. Stobie M, Strode AE, Slack CM. The dilemma of enrolling children in HIV vaccine research in South Africa: What is in 'the child's best interests'? In: Van Niekerk A, Kopelman L, eds. Ethics and AIDS in Africa. Cape Town: David Philip Publishers, 2005:190-207.

12. Essack Z. Ensuring access to HIV prevention services in South African HIV vaccine trials: Correspondence between guidelines and practices. Public Health Ethics 2014;7(2):195-206. DOI:10.1093/phe/phu010

13. Strode A, Slack C. Selected Ethical-legal Norms in Child and Adolescent HIV Prevention Research: Consent, Confidentiality and Mandatory Reporting [revised]. Pietermaritzburg: HIV AIDS Vaccines Ethics Group (HAVEG), 2014:1-8.

4. Bhamjee S, Essack Z, Strode A. Amendments to the Sexual Offences Act dealing with underage sex: Implication for doctors and researchers. S Afr Med J 2016;106(3):256-259. DOI:10.7196/SAMJ.2016.v106i3.9877

5. Editorial. Giving children a chance. Lancet 2013;381(9866):507. DOI:10.1016/S0140-6736(13)60261-5

6. Rwemisisi J, Wolff B, Coutinho A, Grosskurth H, Whitworth J. 'What if they ask how I got it? Dilemmas of disclosing parental HIV status and testing children for HIV in Uganda. Health Policy Plan 2008;23(1):36-42. DOI:10.1093/heapol/czm040

17. Lesch A, Swartz L, Kagee A, et al. Paediatric HIV/AIDS disclosure: Towards a developmental and process-oriented approach. AIDS Care 2007;19(6):811-816. DOI:10.1080/09540120601129301

18. Rochat TJ, Mkwanazi N, Bland R. Maternal HIV disclosure to HIV-uninfected children in rural Rochat TJ, Mkwanazi N, Bland R. Maternal HIV disclosure to HIV-uninfected children in rural
South Africa: A pilot study of a family-based intervention. BMC Public Health 2013;13(147):1-16. DOI:10.1186/1471-2458-13-147

19. Vaz LM, Eng E, Maman S, Tshikandu T, Behets F. Telling children they have HIV: Lessons learned from findings of a qualitative study in sub-Saharan Africa. AIDS Patient Care STDs 2010;24(4):247-256. DOI:10.1089/apc.2009.0217

20. Shisana O, Rehle T, Simbayi LC, et al. South African National HIV Prevalence Incidence Behaviou and Communication Survey 2008: A Turning Tide among Teenagers? Cape Town: HSRC Press, 2009.

21. Strode A, Richter M, Wallace M, Toohey J, Technau K. Failing the vulnerable: Three new consent norms that will undermine health research with children. South Afr J HIV Med 2014;15(2):46-49. DOI:10.4102/hivmed.v15i2.18

22. Gwandure R, Ross E, Gardner, J. Parents perceptions of HIV counselling and testing in schools: Ethical, legal and social implications. S Afr Med J 2014;104(1):40-42. DOI:10.7196/SAMJ.6645

23. Strode A, Toohey J, Slack C, Bhamjee, S. Reporting underage consensual sex after the Teddy Bear case: A different perspective. S Afr J Bioeth Law 2013;6(2):45-47. DOI:10.7196/SAJBL.289

24. Strode A, Slack C. Sex, lies and disclosures: Researchers and the reporting of under-age sex. South Afr Strode A, Slack C. Sex, lies and
J HIV Med 2009;10(2):8-10,

25. Government of South Africa. Criminal Law (Sexual Offences and Related Matters) Amendment Act: No. 32 of 2007. Pretoria: Government Printer, 2007.

26. Teddy Bear Clinic for Abused Children, and Resources Aimed at the Prevention of Child Abuse and Neglect (RAPCAN) v. Minister of Justice and Constitutional Development Case, 2014 (1) SACR 327 (CC).

27. National Departments of Health and Basic Education. Integrated School Health Policy. Pretoria, 2012. http://www health-e.org.za/wp-content/uploads/2013/10/Integrated_School_Health_Policy.pdf (accessed 17 December 2015)

28. Department of Health. Guidelines for Good Practice in the Conduct of Clinical Trials with Human Participants in South Africa. Pretoria: Department of Health, 2006. http://www.kznhealth.gov.za/ research/guideline2.pdf (accessed 17 December 2015).

Accepted 7 January 2016 